\title{
A Declaração dos Direitos Sociais na futura Constituição Brasileira (*)
}

\author{
A. F. Cesarino Júnior
}

\begin{abstract}
SUMÁRIO - 1 Significado da abertura dos cursos jurídicos de 1946. 2 - Continuidade da luta pelo democracia. 3 - A democracia será social ou não será democracia. 4- Evolução da democracia política para a democracia social nos Estados Unidos. 5 - Idêntica evolução no Brasil. 6 - A declaração dos direitos sociais. 7 - A declaração dos direitos sociais na futura Constituição Brasileira. 8-A efetividade dos direitos sociais no Brasil.
\end{abstract}

1 - 'Abrem-se os cursos de 1946 desta Faculdade numa das épocas mais criticas de tôda a História Universal, em pleno limiar da éra atômica. Apenas saídos da mais tremenda das guerras, terminada com uma experiência tão atroz, dé assombrar vencidos e vencedores, encontramo-nos ainda em face de interrogações cada qual mais dolorosa. Ganha a guerra, saberemos ganhar a paz? Até que ponto estamos realmente em pàz? Ha mesmo um descansar de armas, ou existe apenas um ligeiro interludio, em que nos preparamos para um conflito ainda mais dantesco?

Estas preocupações não afligem sòmente aos responsaveis pelas relações internacionais. Dentro de cada país, o reflexo das consequencias da guerra atroz se faz sentir tambem, cada vez mais intenso. A completa desorganização da economia, tanto nacional, como internacional; a considera-

(*) Aula inaugural dos cursos de 1946 da Faculdade de Direito. 
vel diminuição dos bens de uso comum e a crescente remuneração das atividades economicas e profissionais consagradas à produção de guerra; a restrição dos transportes gerais, determinada pelas exigencias das prioridades militares e, sobretudo, a voracidade incontrastada dos aproveitadores, tudo išto gerou no interior de quasi todos os países, nuns mais, noutros menos, um ambiente de profundo descontentamento, próprio à eclosão de desordens tanto mais perigosas quanto muitas vezes utilizadas com evidentes intuitos políticos.

2 - Como as demais nações, o Brasil atravessa presentemente a mesma crise. Até certo ponto como sua repercussão, renova os seus quadros políticos e elabora uma nova estrutura constitucional, preparando-se para ingressar defitivamente num regimen democratico. Para êste ingresso, muito contribuiram, como sóe acontecer sempre, em todos os grandes movimentos civicos da nossa nacionalidade, os continuadores das magnifficas tradições desta casa, lutando, seja nos campos de batalha da Europa contra os algozes da civilização, seja na frente interna, contra os inimigos da liberdade.

Como homenagem a êsses lutadores democraticos, vamos tecer nesta modesta preleção algumas considerações acerca de um dos aspétos que deve ter a nossa futura Constituição, se quizer realmente realizar a democracia no Brasil.

3 - Adolphe Thiers disse em 1871: "La III République Française sera conservatrice ou ne sera pas". Parodiando essa frase repetiu o eminente Gurvitch: "La IV République Française sera sociale ou ne sera pas". (1) De nossa parte, levaremos mais adiante essa afirmação: é a própria democracia, que será social ou não existirá.

Por certo, não ignoramos se apode de mal cunhada a frase democracia social, que seria uma expressão sem sen-

(1) Georges Gurvitch, La Déclaration des Droits Sociaux, New York, 1.944, pg. 20. 
tido. (2) Nada menos exato, porém. E aí está a própria História a demonstrar a inexatidão desta critica, tão eloquentemente, que nem será preciso recorrer à semantica para explicar o sentido especifico (e não genérico), relativo às reivindicações populares de melhoramento de situação economica, que em expressões tais como questão, social, legislação social, democracia social, tem o adjetivo "social".

4 - Com efeito, para não nos alongarmos, respiguemos ligeiramente a evolução da democracia, inclusive na história norte-americana, que mal ou bem temos sempre procurado repetir.

Tomas Elorrieta, em seu magnifico estudo sôbre a genese da democracia, considera quatro fases no nascimento da democracia moderna. A primeira é a Revolução Inglesa do século XVII, que se move dentro do marco da nacionalidade inglesa e só se preocupa com os direitos do povo britanico, mas serve de ocasião para que se invoquem os principios democraticos. As outras três são: a Revolução norte-americana, que proclama as liberdades individuais e politicas, mas reserva sua aplicação à raça branca; a Revolução Francesa, que desenvolve, estes principios, triunfando sôbre os obstaculos tradicionais que a eles se opõem na Europa, e que, segundo a frase de Castelar, chama à liberdade todos os escravos; e a Revolução da Espanha e suas colonias americanas, que fez livres aos escravos, confirmando a Espanha nas Cartas de Cadiz a igualdade jurídica dos espanhoes e dos indios, proclamada já nas leis das Indias e decretando suas antigas colonias, ao conquistar a independencia, a abolição total da escravidão em suas diversas manifestações. (3)

Pois bem, este movimento democratico fôra puramente político, e até mesmo se poderia dizer, anti-social.

(2) A. DE Sampaio Dónia, As Tradições da Faculdade de São Paulo "Revista da Faculdade de Direito", São Paulo, 1945, pg. 266.

(3) La Democracia Moderna (Su Genesis), Madrid, s/d, pg. 15. 
Com efeito, no século XVII houve na Inglaterra duas revoluções. A primeira, a Triunfante Revolução Puritana, chefiada por Cromwell, teve como objetivo ultimo adatar o Estado aos designios dos abastados. Seus chefes eram "homens que negavam aos pobres qualquer direito especial à misericórdia e ao amor divino; que proclamavam, ao invés, serem os ricos os verdadeiros benfeitores da sociedade, dignos, por isso mesmo, de que Deus olhasse por êles e lhes assegurasse o gôzo perpétuo de suas prerrogativas políticas e econômicas". A outra revolução, chamada dos Niveladores e Cavadores da terra, falhou. Seus chefes afirmavam "que era de incontestável equidade que o povo pudesse cavar, lavrar, plantar e habitar terras comunais, sem as alugar, ou pagar arrendamento a quem quer que fôsse" "Cromwell respondeu com a espada - e a invocação seguinte: "Se uma Comunidade tem de perecer, há um certo consôlo em que seja às mãos de homens e não de sêres que pouco diferem dos animais! Se ela tem de sofrer provações, que estas venham de preferência dos ricos do que dos pobres, que no dizer de Salomão, quando se tornam opressores nada deixam atrás de si, antes são como a chuva de enxurrada". "A Gloriosa Revolução de 1688 consolidou para todo o sempre as vitórias da Revolta Puritana". (4)

Outra cousa não aeonteceu com a Revolução norte-americana. Ouçamos Emmet John Hughes: "A guerra mesma foi, em certos sentidos essenciais, uma guerra civil. As classes médías e as massas de trabalhadores deram-se as mãos contra a velha aristocracia agrária, os realistas, que juntaram suas fôrças às de Sua Majestade". "Com a paz, tornouse evidente, que uma das revoluções fôra bem sucedida. As treze colônias estavam libertadas do domínio político estrangeiro. Porém, a revolução social chegou a um término muito diferente - a revolução pela qual as massas popu-

(4) Eмmет John Hughes, Assensão e Decadência da Burguesia (tradução de Cypriano Amoroso Costa), Rio, 1945, pg. 148 e seguintes. 
lares esperançadas se tinham empenhado, essa falhou". "A nação que se fundava em tais condições, estava fadada a sęr, no século XIX, o teatro da grande aventura do liberalismo, o cadinho da economia liberal".

E a Revolução Francesa? Que significou senão o advento político da burguezia? Não disse Mirabeau: "O soberano e os proprietários..., eis do que se compõe o Estado: o soberano na órbita política e as classes proprietárias - êles tão sòmente constituem o Estado"? 'Ademais, citemos ainda Hugues: "No texto constitucional de 1791 ainda mais claramente se expôs o advento político da burguesia. Esse documento baseou-se num dos mais práticos critérios de duas faces, graças ao qual uma classe jamais conseguiu incorporar suas ambições na lei comum. A todos os franceses foram assegurados certos direitos fundamentais de opinião, palavra, justiça e oportunidade. Eram direitos passivos, cujos beneficiários se chamavam cidadãos passivos. Havia além disso, porém, direitos ativos, lògicamente prerrogativa política apenas de cidadãos ativos; só êstes tinham direito de vóto. E, porventura, existiria algum outro modo inteligente de se tornar cidadão ativo - a não ser adquirir a qualidade de membro da classe possuidora, pagando impostos nunca inferiores ao equivalente a três dias de trabalho? E' duvidoso que os homens tenham desde logo percebido como havia de ser elevado o número de cidadãos "passivos", no Estado liberal, no decurso do século seguinte.. Quando deu entrada na Convenção o projeto da Constituição do ano III, foi Boissy d'Anglas que o apresentou. Seu discurso é sumário judicioso do ponto de vista político da classe média. ,Devemos ser governados pelos melhores", afirmou êle, "e êsses são os mais instrui'dos e interessados na manutenção da lei. Ora, com muito poucas exceções homens dessa ordem só se podem encontrar entre os proprietários, que por aí são dedicados ao seu país, às leis que protegem os seus bens e à paz social que os preserva... Um país governado por proprietários é uma verdadeira sociedade civil; aquêle, po- 
rém, em que mandam homens sem posses, vive em estado de natureza". "Deliberadamente ou não, o advento de $\mathrm{Na}$ poleão assegurou a vitória da média francesa"; "O Código Civil, repositório legal da obra da Revolução, proclamou a vitória da concepção burguesa de Economia Política. "O seu mais valioso preceito", escreveu o Juiz Lahary, "é o que consagra o direito de propriedade; tudo mais é apenas a consequência lógica dêste fato". Nas palavras do historiador francês Glasson, "Para dizer a verdade, o trabalhador foi lindamente esquecî́do no Código". Para dizer a verdade inteira, êle não foi esquecido: foi proibido de se organizar e de fazer greve". Uma instituição francesa, a Liga Francesa dos Direitos do Homem o reconheceu plenamente nestas palavras: "A Declaração dos Direitos do Homem e do Cidadão fundou a democracia política. Mas, a evolução social, criando novos problemas, o progresso das ciencias e das técnicas, permitindo novas soluções, estes mesmos principios devem, pela abolição de todos os privilegios, fundar a democracia economica". Proudhon já havia declarado que era preciso completar e equilibrar a Constituição Política, com uma Constituição Social independente, cujo primeiro pilar seria a declaração dos direitos economicos dos grupos e dos individuos, que serviria de base para a instauração da "democracia industrial". E Gurvitch pergunta com toda razão: "Não é evidente que os símbolos jurídicos da liberdade humana não podem ser exatamente os mesmos para vencer no século XVIII à feudalidade política e o absolutismo real e para vencer no século $\mathrm{XX}$ o feudalismo industrial, a oligarquia financeira e a técnocracia!". (5)

Daí para cá, com̄ o advento da grande revolução industrial e os consequentes excessos do liberalismo economico começou a surgir o interesse pela questão social e aos poucos a democracia foi deixando de ser méramente política para tornar-se social. Não, porém, sem encontrar essa evo-

(5) ob. cit., pg. 55. 
lução grande resistencia, como assinala o citado Hughes, repetindo um grande constitucionalista inglês, BAGEHot: "Procurando dissuadir a classe laboriosa de se esforçar pela melhoria de seu estado por meio de medidas legislativas, Bagehot refletia uma das mais habilidosas mutações no evoluir do pensamento sociológico liberal. Numa época em que aspiravam ao predomínio político, haviam os homens do comércio e da indústria formulado o dogma de que tudo se podia-éfetuar pela ação legislativa, dado tão sòmente que esta fôsse orientada por principios "verdadeiros". Tendo alcançado a vitória, porém, quando uma classe inferior reclamou o direito de apelar para essa ação em favor de suas próprias e justificadas pretensões, foi-lhe dito que o processo legislativo ainda tão recentemente definido com tendo competência onimoda, de nada servia para os aludidos fins; e aquêles que se levantaram, pedindo que os governos agissem de modo concreto em beneficio dos pobres, foram acusados de demagogia e convidados a compreender que métodos legislativos não podiam aliviar condições geradas por leis econômicas naturais!"

E para provar que essa resistência veiu até nossos dias bastaria lembrar a luta herculea que o grande Presidente Roosevelt teve de travar, além de outras, com a Côrte Suprema de seu país, a propósito das medidas sintetizadas sob a denominação de "New Deal" Damos a palavra a historiadores norte-americanos: "Varios comerciantes e cidadãos outros bateram às portas dos tribunais. Finalmente a Côrte Suprema tomou uma série de decisões declarando que em algumas destäs leis o Congresso havia exorbitado do direito que lhe dava a Constituição. A Côrte decidiu que o A. A. A. era inconstitucional porque a agricultura podia ser controlada apenas pelos Estados, e não pelo govêrno federal. Também declarou que o N. I. R. A. era inconstitucional e com o mesmo argumento, isto é, que a indústria e os salários podiam ser controlados apenas pelo Estado, e não pelo govêrno federal. Ao mesmo tempo a 
Côrte Suprema declarou que as tentativas dos Estados no sentido de obrigar a indústria a pagar salários justos para as mulheres era inconstitucional. A Côrte resolveu que uma lei de Nova York fixando tais salários interferia com a liberdade do empregador e do operário em estabelecerem um acôrdo atinente ao salário. Tais decisões atrapalharam os que desejavam ajudar o trabalho e a elevação do standard de vida. Quando o govêrno federal procurava dar auxílio, a Côrte Suprema achava que cabia aos Estados tal auxílio. Quando os Estados tentavam fazer isso, entretanto, a Côrte dizia que estavam violando as liberdades estabelecidas na Decima Quarta Emenda". Ninguem melhor do que êle definiu a democracia social, no discurso proferido a 12 de Janeiro de 1944: "Esta Republica — diz o grande estadista - teve o seu início e cresceu até a sua presente força, sob a proteção de certos direitos políticos inalienaveis - entre os quais o direito de livre opinião, de imprensa livre, de livre culto, de julgamento pelo juiz, a liberdade de injustificadas buscas e apreensões. Estes foram nossos direitos à vida e à liberdade. Como nossa nação cresceu em tamanho e importância - contudo - como a nossa economia industrial se expandiu - estes direitos políticos resultaram inadequados para assegurar-nos igualdade no esforço para alcançar a felicidade. Chegamos à clara compreensão do fato de que aquela verdadeira liberdade individual não pode existir sem segurança econômica e independencia. "Os homens necessitados não são homens livres". As pessoas famintas e desempregadas são a materia de que se fazem as ditaduras" E no celebre Discurso das Quatro Liberdades, de 7 de Janeiro de 1941, já havia êle afirmado que delas: "A terceira é a libertação da necessidade, que, traduzida em termos universais, significava entendimentos econômicos, que assegurarão a toda nação uma saudavel vida de tempos de paz em qualquer parte do mundo". Nesse mesmo discurso pregava: "Igualdade de oportunidades para os jovens e os demais. Emprego para aqueles que podem trabalhar. Seguro para os que necessitem dele. Extinção 
dos privilegios especiais para poucos. Preservação das liberdades civis para todos. $O$ aproveitamento dos frutos do progresso científico num mais amplo e constantemente elevado padrão de vida".

5 - Em nosso país também evoluimos para a democracia social. Nossa primeira Constituição, a Carta outorgadada por D. Pedro I a 25 de março de 1824, no art. 179 apenas garantia direitos políticos, pois quasi nada continha de ordem social, a não ser os ns. 24,25 e 31, que dispunham respectivamente: "Nenhum gênero de trabalho, de cultura, indústria ou comércio pode ser proibido, uma vez que não se oponha aos costumes públicos, à segurança e saúde dos cidadãos"; "Ficam abolidas as corporações de ofício, seus juízes, escrivães e mestres", e "A Constituição também garante os socorros públicos". O Ato Adicional de 12 de Agôsto de 1834 nada inovou a respeito.

A Constituição da República de 24 de Fevereiro de 1891 sintetiza a democracia puramente política. Limita-se a garantir no $\$ 24$, do art. 72 , o livre exercício de qualquer profíssão manual, intelectual e industrial, não repetindo a referencia expressa da Constituição do Império à garantia dos socorros públicos. Para dar idéia do seu caráter, bastaria lembrar que, tendo sido acusadas - aqui como nos Estados Unidos - de inconstitucionais as nossas primeiras leis sociais, a Reforma Constitucional de 7 de Setembro de 1926, acrescentou no $n .^{\circ} 28$, do adt. 34 , à matéria da competencia do Congresso Nacional, a de legislar sôbre o trabalho.

Já a Constituição de 16 de Julho de 1934 é notóriamente social-democrata, consagrando um título especial à Ordem Econômica e Social e outro à Família, à Educação e à Cultura. A Carta de 10 de Novembro de 1937 seguiu êste exemplo.

(6) Roy F. Nichols, William C. Bagley e Charles A. Beard, Os Estados Unidos de ontem e de hoje, (Trad. de Carlos Lacerda e Fernando Tude de Sousa) São Paulo, 1941, pg. 413. 
6 - Vemos assim, que já se implantou em nossos dois últimos documentos constitucionais o sistema duma declaração dos direitos sociais.

Aliás, êste sistema não é inovação da Constituição Brasileira. 'A Repärtição Internacional do Trabalho publicou recentemente um alentado volume, contendo as disposições constitucionais sôbre Política Social e Econômica de 450 países e Estados. (7)

E Gurvitch, que escreveu um livro notavel dedicado exclusivamente a êste assunto, nêle apresenta, com base na na sua teoria pluralista do direito, um projéto de Declaraf̧ío dos Direitos Sociais, com 58 artigos. Aí estão enumerados sucessivamente os Direitos Sociais dos Produtores, compreensivos do que êle chama o Direito ao Trabalho, o Direito do Trabaliho, o Direito de Liberdade Sindical e o Direito de Gréve; Os Direitos Sociais dos Consumidores e Clientes, os Direitos e os Deveres sociais decorrentes da Propriealade e, finalmente os Direitos Sociais do Homem. Na Introdução ao seu projéto, cita êle a Nova Declaração dos Direitos publicada em Janeiro de 1943, pelo Instituto de Planificação dos Recursos Nacionais dos Estados Unidos. A XXVI Conferencia Internacional do Trabalho reunida em Abril de 1944 em Filadelfia votou também uma espécie de declaração dos direitos, completando a Carta Internacional do Trabalho contida no art. 427, secção XIII, do Tratado de Versalhes, de 1919. Já em 1936, como vimos, a Liga Francesa dos Direitos do Homem tinha publicado um projéto de Complemento à Declaração dos Direitos do Homem e do Cidadão. (8)

Das Constituições que contêm explicita ou implicitamente Declarações dos Direitos Sociais as principais são as do México, de 1917, da Alemanha, de 1919, da República Espanhola, de 1931, e da União das Repúblicas Socialistas

(7) Internacional Labour Office, Constitucional Privisions. Concerning Social and Economic Policy, Montreal, 1944.

(8) Ob. cit., passim. 
Soviéticas, de 1936, cujos dispositivos seria muito longo analisar aqui, mas foram levados em conta na elaboração do nosso projéto de Declaração dos Direitos Sociais na futura Constituição Brasileira.

Tudo isto evidencia a utilidade de uma Declaração dos Direitos Sociais, utilidade esta demonstrada por Léon Duguit, nesta magnifica síntese: "No apice, a lei suprema, superior a todas as outras, a Declaração dos Direitos. Abaixo, delas, as leis constitucionais, que lhe são subordinadas, mas que são superiores às leis ordinárias. Enfim estas últimas que não podem editar nenhuma disposição contraria às leis constítucionais ou à declaração. O sistema constitue uma possante proteção.. contra o arbítrio legislativo".

'Demonstramos a necessidade de uma Declaração dos Direitos Sociais. Com efeito, os direitos polítilcos dos cidadãos, afirmando-se numa esfera diferente dos direitos sociais dos produtores, dos consumidores e dos clientes, devem ser equilibrados e delimitados por êles.

"Mas, porque a expressão "direitos sociais". Não serả pleonastica? Porventura todo direito não é social? Aproveitamos o ensejo, para contestar não apenas esta objeção, evidentemente simplista, considerando-se a variação semantica do sentido do ađjjetivo "social", a que já nos referimos, mas também uma outra, muito mais importante, de Gurvitch. Diz êle, que o termo Direito Social é muitas vezes usado no sentido dum direito ligado à "política social do Estado", especialmente à legislação do Estado tendo em conta a "questão socĩal" Compreende-se, então como "Direito Social" simplesmente o conjunto das regras jurídicas, e particularmente das leis do Estado, protegendo os elementos fracos e não proprietários da sociedade e dispondo sôbre a intervenção do Estado na ordem económica. E considera esta interpretação do direito social erronea do ponto de

(9) Traité de Droit Constitutionnel, V, III, pg. 644, apud GuRviтсн, $O b$. cit, pg. 49. 
vista teórico e perigosa para a democracia do ponto de vista prático.,

Erronea porque - diz êle - não tem em conta o fenômeno do pluralismo jurídico, implicando uma teoria estatista e monista do direito, que só vê nêle o mandamento dum poder ou duma vontade superior, cuja autoridade suprema seria a do Estado. Não procede, porém, a objeção. Longe de nós a idéia de negar a verdade do pluralismo jurídico. Acontece, porém, que o direito social - nesse sentido - raramente é um direito extraestatal. E o próprio Gurvitch quem o reconhece, ao distinguir as seguintes espécies de Direito Social em suas relações com a ordem jurídica do Estado: $10^{\circ}$ ) o Direito Social puro e independente; $\left.2 .^{\circ}\right) \quad O$ Direito Social puro, mas sujeito à tutéla do direito Estatal; 3.-- O Direito Social autonomo, mas anexado pelo Estado; 4. ) O Direito Social condenscido na ordem jurídica. do Estado democrático. Vê-se por aí como é raro o Direito Social puro e independente. Com efeito, a respeito das próprias convenções coletivas de trabalho, um dos maiores teóricos do Direito Social, Sinzheimer chegou à mesma conclusão: - "a maior parte do direito operário tem a sua fonte fóra das coleções de leis". Assim diz êle que, nos primeiros tempos, quando o direito estatal não conhecia senão a coordenação entre indivíduos jurídicamente iguais, a emprêsa nutria um direito não-estatal, fundado sôbre a idéia de subordinação criado pela vontade dominadora de um só - o patrão, expressa geralmente no unilateral "regulamento de oficina", sendo êste direito não estatal de dominação o verdadeiro direito operário dos primeiros tempos do capitalismo. À forma hierárquica do direito não-estatal sucede a forma coletiva do contrato de trabalho. Os agrupamentos de trabalhadores tiram à relação de trabalho o caráter de criação unilateral. Assim, o direito coletivo se revelou por ter saído do jôgo das forças sociais e não de uma autorização legal. "As normas regulamentando as convenções coletivas nasceram elas próprias 
fóra da lei". O Estado, a principio se defendeu contra êste direito não estatal, depois o transformou por regras imperativas, passando depois a reconhecê-lo, como aconteceu particularmente com as diversas leis que regulamentam as convenções coletivas de trabalho". Estas leis tiveram, com efeito, por fim, garantir o funcionamento juridico do direito coletivo chamado à vida por energias extraestatais". Este reconhecimento apresenta diversos graus: "O estado pode contentar-se com "verificar" a legalidade das convenções; resolve, por disposições positivas as dúvidas que a sua aplicação jurídica pode fazer nascer delas. Mas o Estado pode ir mais longe: põe à disposição dos operários os quadros que favorecem a conclusão das convenções (órgãos de conciliação) ; substitue às convenções a arbitragem obrigatória; enfim, pode estender sua ação além do círculo dos interessados na convenção, declarando obrigatórios para todos certos contratos de tarifas". (10)

Por outro lado, considera GuRvitch perigosa a citada interpretação do Direito Social, porque vê nos menos favorecidos economicamente, nos hipossuficientes como os chamamos, exclusivamente beneficiários e destinatários passivos das medidas beneficentes do Estado. Nada menos exato: em que o reconhecimento pelo Estado dos contratos ou convenções coletivas de trabalho impede a sua realização ou lhes tira o valor? Porque não pode o Estado, embóra legislando sôbre os sindicatos, respeitar-lhes a autonomia?

7 - Nas sugestões que vamos' agora apresentar para a Declaração dos Direitos Sociais na futura Constituição Brasileira não seguiremos o projéto de GuRvitch, embóra nos inspiremos frequentemente nêle. Já dissemos que tem 58 artigos, versando os direitos dos produtores, dos consumidores e clientes e do homem. Encerra ademais a proposta de formação de uma organização corporativa para realização desses direitos.

(10) La Theorie des Sources du Droit et le Droit Ouvrier, in “Le Probléme des Sources du Droit Positif", pgs. 73-81. 
Preferimos seguir a lição da experiência contida nestas palavras da Repartição Internacional do Trabalho: "A moderação é a essencia da sabedoria e uma boa declaração constitucional de política social e econômica deve adotar um oportuno compromisso entre as aspirações e a exequibilidade. Deve ser inspirada por bondade de coração e afeiçoado por dureza de coração. O progresso humano é, na maior parte, um processo de lento crescimento conseguido através de incessante esforço". (11)

Porisso, muito embóra reconheçamos a verdade, por nós mesmos proclamada mais duma vez, da interdependencia entre as leis sociais e as medidas econômicas, tendo em vista aqueles sabios conselhos, vamos expôr um trabalho muito mais modesto, tomando como base as disposiçốes do capítulo da Ordem Economica e Social da Constituição de 16 de Julho de 1934, que seria para nós o melhor projéto para a nossa futura Magna Carta. Quanto aos demais dispositivos, apenas acrescentariamos o Direito Social entre as matérias da competência legislativa da Unjão, mantendo tambem os dispositivos da declaração dos direitos, relativos à profissão e à propriedade.

Assim, acrescentariamos ao Título III, Da Declaração dos Direitos, e que já contem dois capítulos, Dos Direitos Políticos, isto é, dos cidiadãos, e Dos Direitos e das garantias individuais, isto é, dos homens, um terceiro: Dos Direitos Sociais com a seguinte ou equivalente redação.

\section{CAPÍTULO III}

\section{Dos Direitos Sociais}

Art. $10^{\circ}$ - Todo homem valido tem a partir de 14 anos de idade, direito a obter um trabalho de acôrdo com a sua capacidade e o dever de realizá-lo lealmente.

(11) ob. cit, pg. XXI 
Art. 2. - Em retribuição ao trabalho prestado todo empregado tem direito: a) a um salário mínimo, calculado segundo as necessidades de alimentação, vestuário, habitação, higiene, transporte, recreação, educação e previdencia do trabalhador, as possibilidades da produção e a qualidade e quantidade do trabalho fornecido; b) a uma participação nos lucros da empresa para a qual trabalhe; c) a abonos familiares em proporção dos seus encargos de família, pagos por caixas de compensação, organizadas compulsóriamente pelos empregadores.

Art. $30^{\circ}$ - 'A duração diária máxima do trabalho será de oito horas, e a semanal de quarenta e oito horas, salvo as exceções previstas na lei, assegurado o descanso semanal e festivo, sempre que possível aos domingos

Art. $4 . \circ$ - Os locais de trabalho devem ser higienicos, seguros e morais.

Art. $50^{\circ}$ - Depois de um ano de serviço ininterrupto na mesma empresa o empregado terá direito a um mínimo de quinze dias de férias anuais remuneradas, cujo aproveitamento adequado lhe será facilitado pelo Estado.

Art. 6..$^{\circ}$ - São proibidos: qualquer trabalho aos menores de 14 anos; o trabalho noturno aos menores de 16 e os trabalhos insalubres aos menores de 18 anos e às mulheres.

Art. 7. - As gestantes terão direito a repouso remunerado antes e depois do parto e as lactantes à interrupção do trabalho para amamentação.

Art. $8 .^{\circ}$ - A mudança de estrutura jurídica das empresas não altera os contratos individuais de trabalho dos seus empregados.

Art. $90^{\circ}$ - A cessação das relações de trabalho a que o empregado não haja dado motivo, nas empresas do trabalho contínuo, lhe assegura o direito a uma indenização proporcional aos anos de serviço.

Art. $100^{\circ}$ - Os sindicatos de empregados e empregadores poderão acordar contratos coletivos de trabalho, estabelecendo condições de trabalho não inferiores aos mínimos 
legais. 'A requerimento dos interessados poderão tais contratos tornar-se obrigatórios para todos os membros das categorias representados pelos sindicatos convenentes.

Art. $110^{\circ}$ - As questões oriundas das relações entre empregados e empregadores, reguladas na legislação social e as referentes à previdência social serão dirimidas pela Justiça especial do Trabalho.

Parágrafo único. - A Justiça do Trabalho terá composição paritaria quando se tratar de dissidios coletivos de trabalho de natureza econômica.

Art. 12. - Todos os cidadãos e estrangeiros residentes de mais de 14 anos de idade serão obrigatória e eficientemente segurados contra os riscos decorrentes de desemprego, enfermidade, invalidez, inclusive a resultante de acidente do trabalho, maternidade, velhice e morte, em instituições autarquicas de seguro social.

Art. 13. - Os mvalidos, porventura não abrangidos pelo seguro social, terão direito à assistência por parte do Estado.

Art. 14. - A lei garantirá a pluralidade e a autonomia dos sindicatos reconhecidos como órgãos representativos das categorias econômicas e profissionais.

Art. 15. - E assegurado o direito de greve e "lockout", uma vez exgotados os recursos à conciliação e à arbitragem.

Art. 16. - A lei protegerá por todas as formas a economia popular, fomentando o cooperativismo, reprimindo a usura, a concorrencia desleal e todos os abusos no exercício da atividade econômica, suprimindo os impostos indiretos, aumentando a parte progressiva do imposto de renda e tributando os lucros extraordinários.

Art. 17. - A lei dispensará proteção especial à fixação do homem do campo, no ambiente rural, melhorando as suas condições de vida, facilitando o seu acesso à propriedade movel, financiando as atividades agricolas, mecanizando a lavoura e descentralizando a atração urbana. 
Art. 18. - A lei disporá sobre a proteção a ser dispensada ao trabalhador nacional em concorrencia com a mão de obra estrangeira, sem prejuizo da imigração adequada.

Art. 19. - A lei regulará a nacionalização progressiva das minas, jazidas minerais, quedas d'agua e outras fontes de energia, assim como dos acionistas dos bancos de depósito e empresas de seguro e da maioria da administração das empresas concessionárias de serviços públicos

Art. 20. - A lei determinará a publicidade e a responsabilidade dos atos das empresas de serviço público ou diretamente relacionadas com os interesses da coletividade.

Art. 21. - A lei protegerá a solidez da instituição familiar e amparará sempre a maternidade, a infância e a juventude.

Art. 22. - $\mathrm{O}$ ensino oficial será gratuito em todos os seus graus, sendo o primario e o prevocacional obrigatórios, facilitadas aos mais capazes e necessitados bolsas oficiais para prosseguimento dos seus estudos.

Art. 23. - Tôda empresa industrial ou agrícola, fora dos centros escolares, e onde trabalharem mais de cincoenta pessoas, perfazendo estas e os seus filhos, pelo menos dez analfabetos, será obrigada a lhes proporcionar ensino primário gratuito.

Art. 24. - A entrada de imigrantes no território nacional sofrerá as restrições necessárias às garantias da integração étnica e capacidade física e civil do imigrante e dos interesses da defesa nacional e da ordem política e social, vedada sempre a concentração de imigrantes da mesma nacionalidade ou raça em qualquer ponto do território nacional.

Art. 25. - Todo brasileiro que, não sendo proprietário rural ou urbano, ocupar, por dez anos contínuos, sem oposição nem reconhecimento de domínio alheio, um trecho de terra até dez hectares, tornando-o produtivo com o seu trabalho e tendo nêle a sua morada, adquirirá o domínio, mediante sentença declaratória devidamente transcrita. 
8 - Os direitos sociais acima enumerados se justificam pela sua simples enunciação.

Cumpre, portanto, torná-los efetivos, realizá-los, não sòmente fazendo-os constar das leis, mas tornando realidades palpaveis as promessas nêles contidas.

Para isto, ha necessidade de duas medidas: uma destrutiva e outra construtiva.

A primeira consiste em combater dois grandes vícios tipicamente brasileiros: a preocupação com a "fachada" e a excessiva tolerância com as infrações dos deveres públicos.

Quanto à "fachada", que nos faz muitas vezes passar como verdadeiros "novos ricos da civilização", se manifesta em nosso afã de aparentarmos requintes sỏ próprios de países muito mais adiantados, enquanto descuramos problemas elementares, de muito maior importância prática. Assim, dispendemos largas somas em aparatosas missões no estrangeiro, em instituições de alta cultura literária ou artística, em maravilhosos palácios de marmore, suntuosas avenidas e magníficas estatuas, enquanto o nosso homem do campo e muitas vezes da cidade também, morre à míngua dos recursos mais necessários, subalimentado, maltrapilho, vivendo quasi ao relento, minado pelas doenças, analfabéto, numa vida (si é que se póde chamar a isso de vida) quasi próxima à dos animais irracionais. $\mathrm{E}$ até mesmo, não já nas vilas esquecidas, mas nas próprias grandes capitais, pululam os cortiços, as favelas, os porões, é escasso o transporte, faltam os generos de primeira necessidade.

$\mathrm{E}$ tudo isto, além de nosso até aqui incorrigivel exibicionismo, porque? Por causa da nossa falta de espírito público, da nossa excessiva tolerância para com os infratores dos deveres cívicos, por causa do muito brasileiro "dase um geitinho" A lei não permite, mas para os bem relacionados, os amigos, os parentes e. . sobretudo para os endinheirados, tudo ou pelo menos quasi tudo é possivel, guardadas as aparencias de legalidade, naturalmente. . 
A medida construtiva seria representada por uma decisão governamental de estabelecer-se um verdadeiro plano quinquenal ou mesmo decenal, de intenso combate ao pauperismo em nossa terra, notadamente se procurando resolver os três graves problemas da saúde, da educação e dos transportes, de cuja solução dependẹm todos os demais.

Muitas vezes, lendo interminaveis listas de subvenções federais, estaduais e municipais a entidades que se ocupam de atividades perfeitamente superfluas, de verbas para obras puramente suntuarias, mais interminaveis listas de nomeações de funcionários completamente desnecessários, e somando os valores dessas e de outras despesas inuteis, como as de construções oficiais adiaveis e de instalações luxuosas desnecessárias, fico tristemente a pensar nas respostas desalentadoras que encontram sempre dos governantes os reclamos de medidas de salvação pública: a falta de recursos do tesouro público...

Tudo está a indicar, portanto, que não basta uma reforma nas leis, mesmo quando constitucionais. Urge uma reforma nos homens e nos costumes.

Mirabeau, o grande tribuno da Revolução Francesa que eu não vos aponto neste momento como modêlo de costumes. - declarou à Assembleia Nacional, em 1789, que os princípios da Declaração dos Direitos "estavam escritos nos corações".

Pois bem, que os princípios da Declaração dos Direitos Sociais, além de inscritos na futura Constituição Brasileira, fiquem também gravados em nossos corações.

Mas que estes corações tenham a fortaleza necessária para, dominando as nossas fraquezas, vencendo a nossa falta de espírito público, preocupando-se com a realidade e não com a aparência, nos levarem a sua realização, para que o Brasil possa atingir os elevados destinos que o aguardam, si nós, brasileiros, soubermos estar à altura de noss : missão histórica. 